\title{
BIOMETRIA DE NEONATO DE CHELONOIDIS CARBONARIA (Spix, 1824) ASSOCIADA A NUTRIÇÃO.
}

\section{Maiara Cristina Ribeiro Vlahovic ${ }^{1}$ \\ Karla Andressa Ruiz Lopes ${ }^{2}$ \\ Nádia Maria Rodriges de Campos Velho ${ }^{3}$}

Resumo: Os jabutis do gênero Chelonoidis, apresentam hábitos terrestres e são pertencentes à família Testudinidae. O objetivo deste trabalho foi realizar a biometria de neonatos de Chelonoidis carbonaria associada à alimentação, visando à nutrição adequada para os neonatos. Foram selecionados dez indivíduos, de Chelonoidis carbonaria que foram acompanhados por dez semanas, com uma dieta específica. Ao longo de dez semanas foram mensurados, e como resultados obteve-se: crescimento de 3,1 cm do comprimento curvilíneo da carapaça (C.C.C.), 2,94 cm da largura curvilínea da carapaça (L.C. C), 2,30cm do comprimento do Plastrão (C.P) e 2,68 cm da largura do Plastrão (L.P), atingindo o maior crescimento na sexta semana.

Palavras-chave Jabuti-piranga; Morfologia; Alimentação.

\footnotetext{
1 Ciências Biológicas/Universidade do Vale do Paraíba, Brasil. E-mail: mcrv@outlook.com.

2 Ciências Biológicas/Universidade do Vale do Paraíba, Brasil. E-mail: karla@univap.br.

${ }^{3}$ Ciências Biológicas/Universidade do Vale do Paraíba, Brasil. E-mail: nvelho@univap.br.
} 